\title{
IMPLANTAÇÃO DE UM KIT PARA COMUNICAÇÃO DE ACIDENTE DO TRABALHO (KIT- CAT) COMO FACILITADOR DAS AÇÕES QUE ENVOLVEM OS ACIDENTES COM PERFUROCORTANTES
}

\author{
Cristina Maria Fernandes Porto* \\ Mônica Penteado Trentin Lazzarini** \\ Luciana Rigotto Parada Redígolo*** \\ Fátima Regina de Almeida Lima Neves****
}

PORTO, C.M.F.; LAZZARINI, M.P.T.; REDÍGOLO, L.R.P.; NEVES, F.R.A.L. Implantação de um kit para comunicação de acidente do trabalho (KIT-CAT) como facilitador das ações que envolvem os acidentes com perfurocortantes. Rev.latino-am.enfermagem, Ribeirão Preto, v. 7, n. 5, p. 121-126, dezembro 1999.

Este trabalho destaca a criação e aplicação na prática profissional, de um Kit para Comunicação de Acidente de Trabalho com perfurocortantes para a Secretaria Municipal da Saúde de Ribeirão Preto, como um instrumento indispensável à prestação de serviços de assistência à saúde dos funcionários das Unidades de Saúde do município. Evidencia a notificação e início da prevenção das doenças ocupacionais, sendo assim, um instrumento extremamente útil quando da ocorrência do acidente. A criação deste Kit possibilitou a retomada de medidas de prevenção dos acidentes ocupacionais, culminando com a mobilização de servidores e chefias na intensificação das ações preventivas.

\section{UNITERMOS: perfurocortantes, acidentes ocupacionais}

\section{INTRODUÇÃO}

A necessidade da criação de um Kit para Comunicação de Acidente do Trabalho, (CAT) por nós denominado de KIT-CAT, surgiu após a experiência de um membro da Comissão Interna de Prevenção de Acidente (CIPA) da Secretaria Municipal da Saúde (SMS) de Ribeirão Preto, acidentado com perfurocortante, dentro de um serviço ainda não estruturado para este tipo de ação.

A partir deste momento foi organizado um grupo multiprofissional que envolveu Programas e Departamentos da SMS, na discussão de procedimentos recomendados em casos de acidentes ocupacionais, com exposição a material potencialmente contaminado com vírus da Síndrome da Imunodeficiência (AIDS) e da Hepatite B e C.

A nossa constatação foi a de que, até aquele momento, nenhum estudo tinha sido realizado sobre a questão e estávamos diante de muitas interrogações:
- Quantos eram os acidentes com perfurocortantes em nosso serviço?

- Qual a categoria profissional mais exposta a este tipo de acidente?

- Qual o principal objeto causador deste tipo de acidente?

$\mathrm{Na}$ tentativa de responder a estas questões foi feito um questionamento junto a Divisão de Medicina e Segurança do Trabalho (DMST) da Prefeitura Municipal de Ribeirão Preto, com o objetivo de nos orientar sobre o quadro real da situação do nosso serviço.

Os dados apontaram a ocorrência de 32 acidentes com perfurocortantes entre os 79 acidentes de trabalho ocorridos na nossa secretaria, no período entre janeiro a junho de 1997. Destes, 25 ocorreram com perfurações através de agulhas contaminadas e 4 com instrumental odontológico, sendo que 17 dos acidentes envolviam profissionais da enfermagem e 8 da área de odontologia $* * * * *$. Entretanto, a nossa experiência profissional apontava para muitos relatos diários de acidentes que não correspondiam com o levantamento

\footnotetext{
* Enfermeira Coordenadora do Programa de Educação Continuada da Secretaria Municipal da Saúde de Ribeirão Preto-São Paulo ** Enfermeira Coordenadora do Programa de Saúde do Trabalhador da Secretaria Municipal da Saúde de Ribeirão Preto-São Paulo

*** Enfermeira Diretora do Departamento de Enfermagem da Secretaria Municipal da Saúde de Ribeirão Preto-São Paulo **** Enfermeira Coordenadora do Programa Municipal DST/AIDS da Secretaria Municipal da Saúde de Ribeirão Preto-São Paulo ***** Dados fornecidos pelo DMST
} 
apresentado. Haveria uma subnotificação?

No nosso serviço encontramos profissionais que desconheciam as doenças ocupacionais advindas deste tipo de acidente, o que poderia estar sendo relevante para a subnotificação bem como para a minimização das conseqüências resultantes com os acidentes ocupacionais.

Conforme relata JOHNSON \& OLSHAN (1997), a situação do acidente ocupacional com perfurocortante precisa ser divulgada, pois o risco de contaminação pelo vírus da Imunodeficiência Humana (HIV) pelos profissionais de saúde é muito subestimado.

Para os profissionais de saúde, o maior fator de risco de transmissão do HIV e do vírus da Hepatite B e C é o contato com o sangue no ambiente ocupacional.

Vários estudos como os de HENDERSON et al. (1990); ZUCKERMAN (1995); HENRY \& CAMPBELL (1995); CASE (1995); COSTA (1996); BELL (1997) apontam para o risco de contaminação acidental após uma exposição percutânea com material contaminado com sangue, considerando os fatores que aumentam o risco de $0,3 \%$ para o HIV, e de 4 a $10 \%$ para o vírus da Hepatite C (PURO et al., 1995); e até 30 a 40\% para o vírus da Hepatite B (PROTECTION, 1990; HEPATITE, 1995).

Dentre os fatores que expõem ao risco, podemos citar ferimentos profundos com sangue visível no material causador do ferimento, acidente envolvendo grande volume de sangue, maior tempo de exposição a secreções, presença de lesões na pele ou mucosa exposta, entre outros.

Segundo MACHADO et al. (1992), levando em conta os freqüentes aspectos emocionais que se seguem a acidentes desta natureza, é recomendável manter os profissionais de saúde, mais intensamente expostos ao risco, orientados quanto a atual dimensão do problema da AIDS no nosso meio.

A nossa experiência profissional frente aos acidentes nas nossas unidades de saúde, apontava para dificuldades relacionadas com as guias de (CAT), que não eram encontradas com facilidade, com o fluxo a ser seguido pelo servidor para iniciar a quimioprofilaxia após o acidente e com o cumprimento das ações trabalhistas decorrentes dos mesmos.

Com base no exposto e frente à constatação de que a AIDS e as Hepatites $\mathrm{B}$ e $\mathrm{C}$ vêm despertando a atenção para várias situações de risco aos profissionais da saúde, (BRASIL, 1998; BRÍGIDO \& PINHEIRO, 1996) que até então estavam relegadas a segundo plano, e diante do desafio de adotar uma nova postura de biossegurança profissional, nos propusemos a criar o KITCAT com o objetivo de padronizar condutas, frente ao acidente profissional, com material perfurocortante, buscando respostas adequadas aos riscos de exposição dos nossos profissionais, que até o momento adotavam procedimentos de biossegurança, desnecessários e, por vezes até onerosos, ou eximiam-se de qualquer cuidado, ficando expostos aos riscos das doenças ocupacionais.

\section{PROCESSO METODOLÓGICO}

A partir de nossas observações expostas no presente estudo e tendo como objetivo facilitar as ações preventivas pós-acidentes com perfurocortantes, procuramos reunir em um único local KIT-CAT as informações e materiais necessários que possibilitassem, de forma sistemática e rápida, o início desta prevenção.

Sobressaem os presupostos de BEECKMANN et al. (1994); COSTA (1996) de que a profilaxia deve ser iniciada imediatamente, nas primeiras horas, após a exposição. Estudos realizados em animais sugerem que de 24 a 36 horas após o acidente, esta profilaxia não é eficiente. Porém, e em especial nos casos de maior risco, a profilaxia deve ser iniciada mesmo após transcorrido esse tempo, pois, mesmo que a infeção não seja prevenida, o tratamento precoce da infeção aguda é benéfico. BRÍGIDO \& PINHEIRO (1996); PROTECTION (1990); CIESIELSKI \& METLER (1997), indicam que o uso profilático do AZT (Zidovidina - ZDV) resultou em uma redução de $79 \%$ do risco de soroconversão após acidente em um estudo de caso-controle com profissionais de saúde.

Para tanto, prosseguimos nas seguintes etapas de implantação do KIT-CAT:

1. Organização do KIT-CAT;

2. Elaboração do Manual de Utilização do KIT-CAT;

3. Oficialização das novas condutas frente aos acidentes com perfurocortantes.

\section{1-) Organização do KIT-CAT}

O KIT-CAT é uma caixa plástica, de $35 \mathrm{~cm}$ x 22 cm contendo:

- 04 vias de impressos de CAT, sendo 01 para o funcionário acidentado, 01 para a DMST, 01 da Divisão de Recursos Humanos e 01 para a CIPA.

- 02 frascos de $10 \mathrm{ml}$ para coleta de sangue de sorologia (sistema de coleta a vácuo), sendo 01 para o funcionário acidentado e 01 para o paciente "fonte" (aquele com que o funcionário esteve envolvido realizando algum procedimento, quando ocorreu o acidente).

- 02 impressos para pedido de exame de laboratório.

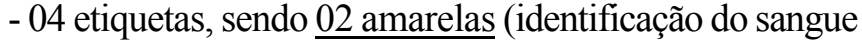
e pedido de exame do funcionário acidentado), e $\underline{02}$ vermelhas (identificação do sangue e pedido de exame do paciente "fonte").

- Cópia do manual com os procedimentos a serem seguidos pelo funcionário acidentado.

- 01 termo de responsabilidade caso o funcionário se recuse a seguir as condutas preconizadas. 
Para cada uma das 26 Unidades Básicas de Saúde (UBSs) e 5 Unidades Básicas Distritais de Saúde (UBDSs), foi enviado um KIT-CAT, assim como para as viaturas do Sistema de Atendimento Médico de Urgência (SAMU) da SMS.

\section{2-Elaboração do Manual de Utilização do KIT-CAT}

Com base nas nossas observações, pudemos constatar que os funcionários após o acidente ocupacional com perfurocortantes, experenciavam uma sensação de inércia, com medo de ter se contaminado, o que poderia contribuir para que o mesmo tivesse dificuldade com o fluxo a ser seguido após o acidente.

"Naquele momento, se o virus penetrara em meu corpo, só me restava esperar que o meu sistema imunológico fosse capaz de detê-lo. Mas não suportava a idéia de não fazer nada, de só observar e esperar que o meu erro explodisse num pesadelo" JOHNSON \& OLSHAN (1997).

Elaboramos então o Manual de Prevenção de Acidentes com Perfurocortantes, que além de toda uma abordagem de biossegurança, contém um módulo denominado "QUANDO OCORRE O ACIDENTE", determinando o fluxo que descrevemos abaixo:

\section{$1^{\text {a }}$ - Conduta:}

- Quando houver contaminação de olho e mucosa, lavar o local com água corrente.

- Quando houver contaminação por contato com sangue ou perfuração da pele, lavar o local com água e solução de Poli-Vinil Pirrolidona Iodo(PVPI).

Em um estudo da BECTON DICKINSONAPECIH (1992) junto a 14 dos principais hospitais da Grande São Paulo, apenas 6\% lavavam o local da lesão do acidente com PVPI., sendo que 50\% faziam a expressão do local, o que não é recomendado.

\section{$\mathbf{2}^{\mathbf{a}}$ - Conduta:}

- Preenchimento da guia de CAT em 4 vias, sendo que esta poderá ser preenchida pela chefia imediata e o laudo de exame médico pelo médico da própria unidade de saúde.

\section{$3^{\mathrm{a}}$ - Conduta:}

- Colheita do sangue do paciente "fonte" para HIV e do funcionário acidentado para HIV, Hepatite B e Hepatite C.

Após a colheita, o sangue deverá ser transportado em até, no máximo, 48 horas ao laboratório de referência, e, para isso, foi estruturado um serviço especial junto ao setor de transporte da nossa secretaria.

\section{$4^{\mathrm{a}}$ - Conduta:}

- Ida do funcionário acidentado até a Unidade de Tratamento das Doenças Infecciosas (UETDI) do Hospital das Clínicas da Faculdade de Medicina de Ribeirão Preto-USP, nas primeiras horas após o acidente segundo o preconizado por BEEKMANN et al. (1994). Este serviço tem funcionamento ininterrupto inclusive nos finais de semana.

A SMS instituiu a vacinação contra a Hepatite B para toda Equipe de Enfermagem, Odontológica e Médica bem como para os Auxiliares de Serviço e Motorista de Ambulância.

Caso o servidor não possua o esquema completo de vacina contra a Hepatite B, o Serviço de Assistência Médica dos Servidores Municipais de Ribeirão Preto (SASSOM), fornecerá a Gamaglobulina ( HBIg) ao funcionário acidentado.

Em todos os casos de exposição, um esquema combinado de HBIg (PROTECTION, 1990; BEECKMANN et al., 1994), com a vacina da Hepatite $\mathrm{B}$, proporcionará proteção tanto a curto quanto a longo prazo. A simples dose de HBIg deve ser dada tão logo possa ter a possibilidade depois da exposição e dentro de um limite de 24 horas.

\section{$5^{a}$ - Conduta:}

- O funcionário acidentado deverá comparecer na DMST, onde além de comunicar o acidente, cumprirá com as obrigações trabalhistas decorrentes do mesmo.

\section{$6^{\mathbf{a}}$ - Conduta:}

- O funcionário acidentado comparecerá na Divisão de Recursos Humanos da SMS com a via da (CAT), da própria (DMST) e a da CIPA.

\section{$7^{\mathrm{a}}$ - Conduta:}

- O funcionário acidentado deverá procurar a Unidade II do SASSOM, onde contará com uma equipe formada por Médicos, Enfermeiros, Psicólogos, Assistentes Sociais dentre outros profissionais, para orientá-lo durante todo o seu tratamento.

Neste local ele receberá o resultado do exame de sangue colhido.

O resultado do exame de sangue do paciente "fonte", será entregue ao paciente pelas enfermeiras da unidade de saúde onde ocorreu o acidente.

\section{3 - Oficialização das novas condutas frente aos acidentes com perfurocortantes}

ANGERAMI (1993) diz que quaisquer que sejam as idéias, elas pertencem a indivíduos que se dispuseram a expressá-las. São eles, portanto, os responsáveis por sua coerência e seus defensores naturais. "Tais indivíduos são capazes de sensibilizar outros indivíduos e instituições".

Foi com este pensamento que iniciamos o processo mais difícil na implantação do KIT-CAT, onde tivemos que mobilizar servidores e chefias na intensificação das ações preventivas dos acidentes.

Os fóruns de ação foram as reuniões mensais com Gerentes das UBSs e UBDSs, bem como reuniões 
menores com grupos específicos como dos Enfermeiros da Vigilância Epidemiológica, do Grupo de Capacitação em Prevenção das DST/AIDS, dentre outros, atingindo um total de 160 profissionais inicialmente orientados em relação as novas condutas.

Acreditando ser este um projeto inovador que necessitava de uma nova postura profissional, que, com certeza, necessitaria atingir um maior número de profissionais para a multiplicação das condutas (BRASIL, 1998) e para tanto, em um segundo momento organizamos o curso Biossegurança e Acidentes com Perfurocortantes, atingindo 120 profissionais entre as categorias de Enfermagem e Odontólogos.

Contamos ainda com a colaboração do Departamento Odontológico que designou 01 CirurgiãoDentista para orientar os outros profissionais do serviço de odontologia sobre a correta utilização do KIT-CAT no próprio local de trabalho.

\section{RESULTADOS}

Apesar das peculiariedades inerentes a cada unidade de saúde, os profissionais que participaram dos fóruns de implantação do KIT-CAT, relataram que era a falta de conhecimento do fluxo a ser seguido em caso de acidente ocupacional com material perfurocortante, que contribuía para a subnotificação dos acidentes.

Diante do fato de estarmos apresentando um elemento facilitador frente aos acidentes ocupacionais, os profissionais representantes de cada unidade de saúde, que receberam o treinamento, de uma maneira geral, se comprometeram a ser um multiplicador das novas condutas em seu local de trabalho. Esse fato contribuiu para que de imediato pudéssemos atingir as 35 unidades de saúde do município.

Conseguimos a sensibilização das chefias, com vista a solucionar a falta de Equipamentos de Proteção Individual (EPIs) e Equipamentos de Proteção Coletiva (EPCs), obtendo de imediato, a compra de um maior número de aventais e óculos de proteção, bem como a implantação do descartador para agulha de Carpule (agulha de anestésico), de uso odontológico.

A BECTON DICKINSON-APECIH (1992) nos mostra que o resultado de uma campanha com perfurocortantes pode apresentar um aumento de $7 \%$ das notificações e $14 \%$ de maior conscientização.

Os nossos dados nestes dois primeiros meses de implantação do KIT-CAT apontam para um aumento no número de notificações em torno de $68,85 \%$, uma vez que tivemos 18 acidentes notificados em julho e agosto de 1998, com perfurocortantes, contra 32 entre janeiro e junho de 1997.
Frente ao exposto, entendemos que a implantação do KIT-CAT ofereceu subsídios organizacionais para o trabalho preventivo em relação aos acidentes nas unidades de saúde, bem como trouxe contribuições importantes a saúde ocupacional dos profissionais envolvidos com o acidente.

\section{CONSIDERAÇÕES FINAIS}

Conforme a Legislação Nacional, em acordo feito na $73^{\text {a }}$ Reunião realizada em Genebra, pela Organização Internacional do Trabalho (OIT), FUNDACENTRO (1990) todo trabalhador pode recusar-se a trabalhar em uma situação de perigo, quando tem motivos razoáveis para crer que tal situação seja grave e de iminente risco para sua segurança e saúde.

Considerando que a nossa finalidade enquanto agentes de saúde, é a atenção integral ao usuário do sistema, imprescindível se faz que essa assistência seja extensiva aos funcionários das unidades de saúde, considerando-o enquanto pessoa, com aspectos emocionais que se seguem a acidentes dessa natureza, cumpre-nos destacar a necessidade de condutas padronizadas e ágeis para a notificação e prevenção de acidentes ocupacionais.

A partir dessa avaliação, a necessidade de uma conduta orientadora eficaz, ágil e prática se faz presente, devendo ser de forma organizada, possibilitando informações que sejam realísticas, enquanto o acidentado ainda experimenta a sensação de medo de ter sido contaminado.

A fim de que este projeto inovador, junto a Secretaria Municipal da Saúde de Ribeirão Preto, atinja a maximização na qualidade de assistência aos acidentados com perfurocortantes, a equipe multiprofissional precisa conhecer e compreender esses resultados, reconhecendo que a comunicação se faz imprescindível.

Para nós, que iniciamos este trabalho, foi gratificante observar as inúmeras indagações e consultas que tivemos por parte dos servidores das nossas unidades de saúde, monstrando-nos que restabelecemos a relação entre doenças e acidentes ocupacionais e o trabalho, e caminhamos agora para a melhoria da prevenção e da qualidade de vida do nosso serviço.

Nosso projeto futuro é o monitoramento de todos os acidentes e o processo analítico deles, para a adequação dos nossos serviços no atendimento das necessidades levantadas, visando um atendimento globalizado para o trabalhador, atuando desde a prevenção do acidente até a cura. 


\section{IMPLEMENTATION OF A KIT FOR THE COMMUNICATION OF OCCUPATIONAL ACCIDENTS (KIT CAT) AS A FACILITATOR FOR THE ACTIONS INVOLVING PUNCTURE CUTTING ACCIDENTS}

This paper emphasizes the creation and application of a KIT for the communication of occupational accidents with puncture-cutting objects to the Municipal Health Bureau from the city of Ribeirão Preto. It is an essential instrument for the health care services directed to all the employees of the Health Units. It also evidences the notification and the beginning of the prevention of occupational diseases, being a highly useful instrument whenever any accident occurs. The creation of this KIT enabled the use of prevention measures regarding occupational diseases, culminating with the mobilization of the chiefs and the staff in order to intensify preventive procedures.

\section{IMPLANTACIÓN DE UN KIT PARA COMUNICACIÓN DE ACCIDENTE DE TRABAJO (KIT CAT) COMO FACILITADOR DE LAS ACCIONES QUE INVOLUCRAN LOS ACCIDENTES CON PERFUROCORTANTES}

Este trabajo destaca la creación y aplicación en la practica profesional de un KIT para Comunicación de Accidente de Trabajo con perfurocortantes para la Secretaría Municipal de la Salud de Ribeirão Preto, como instrumento indispensable a la prestación de servicios de asistencia a la salud de los funcionarios de las Unidades de Salud del Municipio. Evidencia la notificación y el inicio de la prevención de enfermedades ocupacionales, siendo así, un instrumento extremamente útil cuando de la ocurrencia del accidente. La creación de este KIT, ha posibilitado la retomada de medidas de prevención de los accidentes ocupacionales, culminando con la movilización de servidores y jefes en la intensificación de las acciones preventivas.

TÉRMINOS CLAVES: perfurocortantes, accidentes ocupacionales

\section{REFERÊNCIAS BIBLIOGRÁFICAS}

01. ANGERAMI, E.L.S. O mister da investigação do enfermeiro. Rev.latino-am.enfermagem, Ribeirão Preto, v. 1, n. 1, p. 11-22, 1993.

02. BECTON DICKINSON-APECIH. Avaliação de procedimentos com relação a acidentes com perfurocortantes. São Paulo: B-D, 1992. p. 56.

03. BEECKMANN, S.E. et al. Temporal association between implementation of universal precautions and a sustained, progressive decrease in percutaneous exposure to blood. Clin. Infect. Dis., v. 18, p. 562-9, April 1994.

04. BELL, D.M. Occupational risk of human immunodeficiency virus infection in healthcare workers: na overview. Am. J. Med., v. 102, n. 19, p. 9-15, May 1997.

05. BRASIL. Governo Democrático e Popular. Cartilha de biossegurança e quimioprofilaxia da exposição ocupacional ao HIV. Brasília: Departamento de Saúde Pública, 1998.

06. BRÍGIDO, L.F.M.; PINHEIRO, M.C. Procedimentos frente a acidentes de trabalho com exposição à material potencialmente contaminado com vírus da AIDS (HIV). Bol.Epidemiol. AIDS, semana 23 a 35, p.3-5,1996.
07. CASE control study of HIV seroconversion in healthcare workers after percutaneous exposure to HIVinfected blood-France, United Kingdom, and United States, January 1998 - August 1994. MMWR, v. 44, n.50, p. 929-33, Dec. 1995. (Capturado da Internet http://aepo-xdvwww.epo.cdc.gov/wonder/PrevGuid/m0039830/ m0039830.htm,02/09/98).

08. CIESIELSKI, C.A.; METLER, R.P. Duration of time between exposure and seroconverssion in healthcare workers with occupationally acquired infection with human immunodeficiency virus. Am. J. Med., v. 102, n. 19, p. 115-6, May 1997.

09. COSTA, J.C. Recomendações provisórias para o uso profilático de antiretrovirais após exposição ocupacional ao vírus do HIV, do pessoal da saúde do Hospital das Clínicas da Faculdade de Medicina de Ribeirão Preto USP. Ribeirão Preto: HCFM-USP, 1996.

10. FUNDACENTRO. Manual sobre condições de trabalho na construção civil. São Paulo: FUNDACENTRO, 1990. (Série Engenharia Civil, 5). 
11. HENDERSON, D.K. et al. Risk for occupational transmission of human immunodeficiency virus type 1 associated with clinical exposures. Ann. Intern. Med., v. 113, n. 10, p.744-6, Nov. 1990.

12. HENRY, K.;CAMPBELL, S. Needlestick/ sharps injuries and HIV exposure among health care workers. Minn.Med., v. 78, n. 11, p. 41- 4, Nov. 1995.

13. HEPATITE por vírus B. Rev.Pediatr.Mod., v. 31, n. 5, p. 847-60, Agosto 1995.

14. JOHNSON, M.; OLSHAN, J. Possível milagre. São Paulo: Schwarcz, 1997.

15. MACHADO, A.A. et al. Risco de infecção pelo vírus de imunodeficiência humana (HIV) em profissionais da saúde. Rev.Saúde Pública, São Paulo, v. 26, n. 1, p. 54-6, 1992.
16. PROTECTION against viral hepatitis. Recommendations of the immunization pratices adwisory committee (ACIP). MMWR.Morb.Mortal.Wkly.Rep., v. 39, n. RR2, p. 1-26, Feb. 1990.

17. PURO, V.; PETROSILLO, N.; IPPOLITO, G. Risk of hepatitis $\mathrm{C}$ seroconversion after occupational exposures in health care workers. Am.J.Infect.Control, v. 23, n. 5, p. 273-277, Oct. 1995.

18. ZUCKERMAN, A.J. Occupational exposure to hepatitis B virus and human immunodeficiency virus: a comparative risk analysis. Am.J.Infect.Control, v. 23, n. 5, p. 286-9, Oct. 1995. 